ARTIGO ORIGINAL

\title{
UTILIDAD DE LA TÉCNICA
}

DE AGLUTINACIÓN DIRECTA

EN EL DIAGNÓSTICO

DE LA INFECCIÓN CHAGÁSICA

Diego Antonio Mendicino, Mirtha Leonor Streiger, Mónica Lilian del Barco, Diana Lucrecia Fabbro, María Laura Bizai y Rafaela Martínez ${ }^{1}$

\section{RESUMEN}

La técnica de aglutinación directa para diagnóstico de infección chagásica es sencilla y económica. Tiene buena sensibilidad y especificidad cuando es utilizada junto con otras técnicas serológicas y/o parasitológicas. Ha sido reemplazada por otras reacciones de mayor rapidez en los resultados y más fácil lectura (ELISA, hemaglutinación indirecta). Actualmente es difícil conseguir equipos comerciales. Se presentan en el siguiente trabajo una serie de casos que muestran la utilidad de la aglutinación directa para determinar precozmente infección aguda y/o congénita y para diferenciar infecciones agudas de crónicas.

DESCRITORES: Chagas. Diagnóstico. Aglutinación directa. Trypanosoma cruzi.

\section{INTRODUCCIÓN}

Las técnicas utilizadas para diagnóstico de enfermedad de Chagas, dependen del momento en que el individuo se encuentre cursando la infección: en el período agudo, como la parasitemia suele ser elevada, se buscan los protozoos circulantes como tripomastigotes en sangre periférica (los anticuerpos [Ac]- IgM de fase aguda no se dosan de rutina), mientras que en la etapa crónica la búsqueda está orientada a la detección de Ac IgG específicos (4, 5, 11, 23). El diagnóstico de los recién nacidos $(\mathrm{RN})$ infectados por vía congénita debe detectar al parásito circulante o diferenciar los Ac del hijo (IgM) de los de la madre (IgG), ya que sólo estos últimos pueden ser transferidos pasivamente a través de la placenta $(10,26,27)$.

1 Centro de Investigaciones sobre Endemias Nacionales Dr Ramón Carrillo (C.I.E.N.), Facultad de Bioquímica y Ciencias Biológicas (F.B.C.B.), Universidad Nacional del Litoral (U.N.L.)

Dirección para correspondencia: Diego Mendicino. Centro de Investigaciones sobre Endemias Nacionales. Facultad de Bioqca y Cs Biológicas, UNL. Ciudad Universitaria, Paraje El Pozo, CP 3000, Santa Fe, Argentina. E-mail: dmendicino@fbcb.unl.edu.ar E-mail alternativo: mlstreiger@yahoo.com

Recibido para publicación en: 10/11/2009. Versión revisada en 4/11/2010. Aceptado en: 16/3/2011. 
La reacción de aglutinación directa $(\mathrm{AD})$ fue una de las técnicas serológicas adicionales utilizadas para la detección de Ac para infección por Trypanosoma cruzi $(2,10,16,17,18,19,24,25)$. Es una técnica de realización sencilla y de relativo bajo costo.

Consiste en una reacción de titulación en policubetas, utilizando como antígenos (Ag) epimastigotes de $T$. cruzi, tratados enzimáticamente y fijados con formaldehído. La formación de un manto de aglutinación en el pocillo indicará la presencia de Ac, mientras que en su ausencia se formará un botón en el fondo del pocillo (25).

El tratamiento previo de las muestras de suero con un agente reductor -2 mercaptoetanol (2-ME) permite eliminar aglutininas inespecíficas que pueden producir resultados falsos positivos.

De esta manera, si se procesan las muestras sin 2-ME la aglutinación se debe a los Ac totales $(\operatorname{IgM}+\operatorname{IgG})$, mientras si se realiza en las mismas una incubación previa con 2-ME, la aglutinación es producida solamente por IgG. Por lo tanto, si se produce una caída de por lo menos 3 títulos procesando simultáneamente una muestra con y $\sin 2-\mathrm{ME}$, se deberá a la presencia de Ac de tipo IgM, y por ende se tratará de una infección aguda. Si la reacción de AD de muestras sin y con 2-ME (AD sin/con 2ME), da como resultado títulos elevados superiores al titulo de corte y similares (iguales o con una pequeña caída), estaremos frente a una infección crónica.

Adicionalmente, como esta reacción detecta Ac dirigidos contra Ag de superficie del protozoo, brinda resultados positivos más precozmente que otras técnicas serológicas que identifican Ac contra Ag citoplasmáticos.

La principal desventaja metodológica está dada por las dificultades en la visualización de las formas de la aglutinación (mantos o botones), que brindan imágenes opalescentes blanquecinas (15). Este inconveniente se puede mejorar coloreando el buffer de reacción o los parásitos ya tratados.

La aparición de técnicas de lectura más fácil, algunas con mejoras en la sensibilidad y especificidad, como Hemoaglutinación Indirecta (HAI), Inmunofluorescencia Indirecta (IFI) y ELISA $(7,14)$, condujo al desuso de la reacción de $\mathrm{AD}$ para Chagas, siendo actualmente utilizada en muy pocos laboratorios.

Sin embargo, antes de los años ' 80 , muchos de los autores mencionados, destacaron la importancia y utilidad de la reacción de $\mathrm{AD}$, respetando la normativa de concordancia en por lo menos dos reacciones serológicas diferentes para arribar al diagnóstico $(6,13,15)$.

El objetivo del presente trabajo es mostrar una serie de casos en los que se vuelven a poner de manifiesto las ventajas de la reacción de $\mathrm{AD}$.

\section{MATERIAL Y MÉTODOS}

Población

Casos de niños o adultos diagnosticados como Chagas agudo (vectorial, congénito, por transplante), reagudizaciones o crónicos, obtenidos por muestreo 
y seguimiento de embarazadas, o por derivación de Servicios de Salud a nuestro Centro (C.I.E.N., Santa Fe, Argentina) en distintos períodos de tiempo (desde 1977 hasta 1996).

Métodos

Como reacciones serológicas se emplearon tres métodos: la inmunofluorescencia indirecta con antígeno preparado según técnica descripta por Streiger y col (20), utilizando como antisuero, anti inmunoglobulina humana total (Ig total) marcada con isotiocianato de fluoresceína (Instituto Pasteur Producción, París, Francia). No se utilizó anti IgM. La técnica fue según lo descripto por Alvarez $\mathrm{y} \operatorname{col}(1)$.

Un segundo método fue la aglutinación directa, con antígeno preparado según técnica de Vattuone y Yanovsky (25) y técnica según lo descripto por Yanovsky (27).

Como tercer método, la hemoaglutinación indirecta con antígeno de la fracción soluble de epimastigotes de $T$ cruzi obtenida por congelamientosdescongelamientos sucesivos, adsorbidos a glóbulos rojos según técnica de Boyden (3) y Hoshino Shimizu (12). La técnica según lo descripto por Cerisola (5) y/o Kits comerciales (Wienerlab $\odot$ ).

Los antígenos utilizados en las reacciones serológicas, de preparación propia, provenían del área de cultivo de nuestro Centro. Dicha área mantiene la cepa de epimastigotes de $T$ cruzi por repiques sucesivos. Se empleaban los sobrantes de masa húmeda.

Como métodos parasitológicos, se usó la gota fresca, el método de Strout y/o el xenodiagnóstico $(\mathrm{Xd})(4,23)$

El examen clínico fué realizado por pediatra, clínico o cardiólogo en nuestro Centro, o en los Servicios de donde habían sido derivadas las personas.

Para el tratamiento se utilizaron dos fármacos, Nifurtimox y Benznidazol. Las dosis y tiempo de duración según recomendaciones nacionales, para niños o adultos, al momento de su administración.

\section{RESULTADOS Y DISCUSIÓN}

En la Tabla 1 se muestran casos de Chagas agudo, con sus evaluaciones clínicas, serológicas y parasitológicas, pre y post tratamiento tripanocida.

En algunos de los niños la clínica y los métodos parasitológicos facilitaron el diagnóstico. En los niños GTC (Caso 1) y AR (Caso 4) la reacción de ADs/ c2ME permitió diagnosticar precozmente la infección chagásica aguda (más de 8 y 6 títulos de diferencia respectivamente), aún antes que la técnica de Strout. La presencia de Ac IgM fue una señal que condujo a una búsqueda minuciosa del parásito en la segunda muestra, que resultó positiva en ambos casos. 


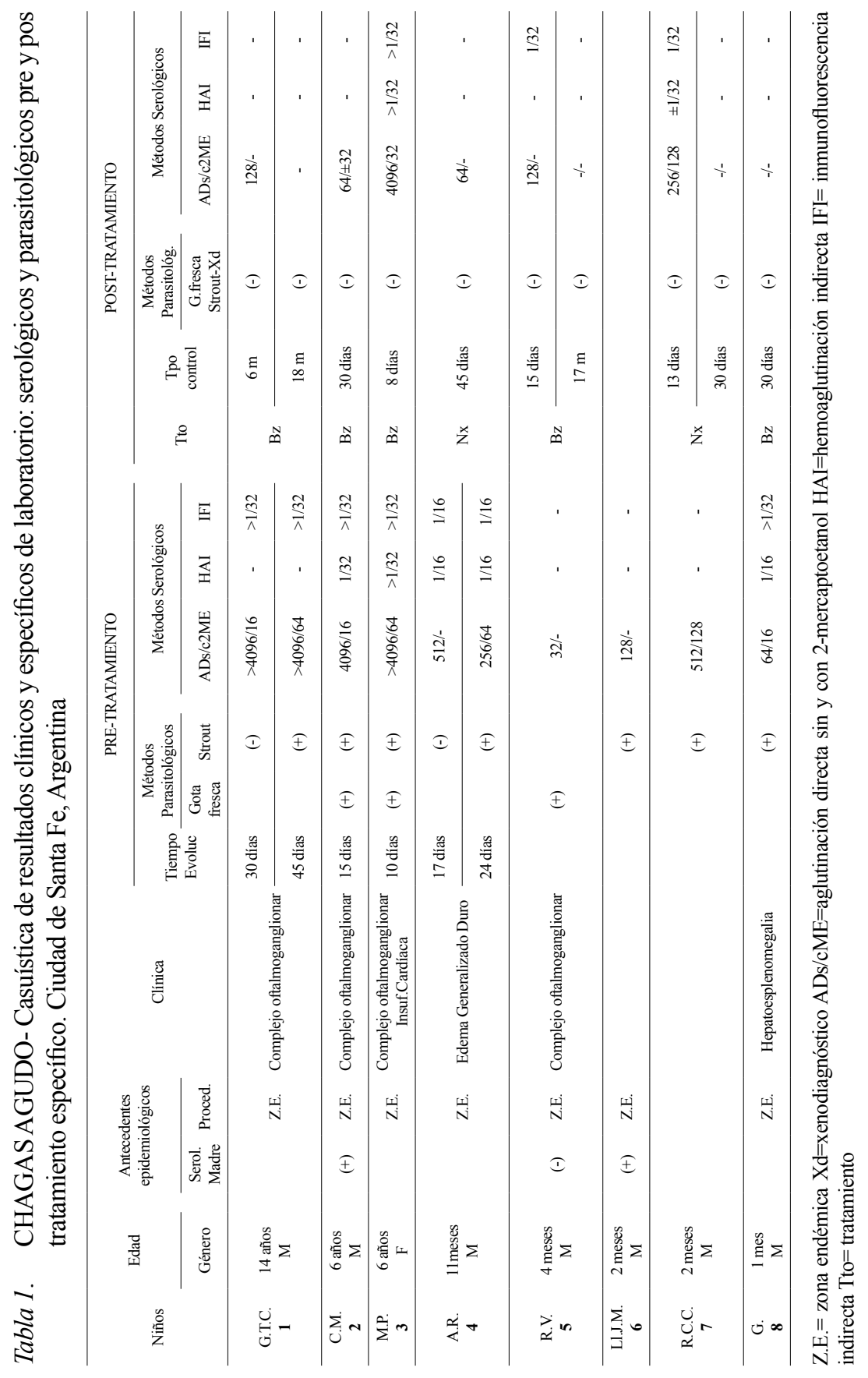


La serología mediante HAI e IFI fue negativa en los controles del niño AR (Caso 4), si bien la IFI sólo se realizó con anti Ig total.

En otros dos niños de 6 años, CM y MP (Casos 2 y 3, con gota fresca positiva), la detección de IgM mediante la ADs/c2ME fue muy notoria a los 10 y 15 días, respectivamente, de iniciados los síntomas. No se observó lo mismo en niños de menor edad.

En la Tabla 2 vemos ejemplos de seguimiento serológico y parasitológico de recién nacidos $(\mathrm{RN})$, hijos de madres con serología positiva $\mathrm{S}(+)$ para $T$ cruzi, que no contrajeron la infección, y en Tabla 3 se observan los $\mathrm{RN}$ diagnosticados con Chagas materno-fetal y tratados posteriormente (21).

Tabla 2. RN hijos de Madre chagásica: Seguimiento parasitológico y serológico. Ciudad de Santa Fe (Arg). Algunos ejemplos de niños NO INFECTADOS

\begin{tabular}{|c|c|c|c|c|c|c|}
\hline \multirow{2}{*}{ Nombre } & \multirow{2}{*}{ Edad } & \multicolumn{2}{|c|}{ Métodos Parasitológicos } & \multicolumn{3}{|c|}{ Métodos Serológicos } \\
\hline & & Strout & $\mathrm{Xd}$ & $\mathrm{AD} / \mathrm{AD} 2-\mathrm{ME}$ & HAI & IFI \\
\hline \multirow[t]{5}{*}{ T. S. } & S. de cordón & $(-)$ & $(-)$ & $1024 / 512$ & $>1 / 32$ & $>1 / 32$ \\
\hline & $1 \mathrm{mes}$ & $(-)$ & & $1024 / 1024$ & $>1 / 32$ & $+1 / 32$ \\
\hline & 2 meses & $(-)$ & & $128 / 64$ & $>1 / 32$ & $+1 / 32$ \\
\hline & 5 meses & $(-)$ & & $\pm 32 / \pm 32$ & $(-)$ & $(-)$ \\
\hline & 10 meses & $(-)$ & & $-/-$ & $(-)$ & $(-)$ \\
\hline \multirow[t]{6}{*}{ L. A. } & S. de cordón & $(-)$ & $(-)$ & $256 / 128$ & $>1 / 32$ & $>1 / 32$ \\
\hline & $1 \mathrm{mes}$ & $(-)$ & & $32 / 32$ & $>1 / 32$ & $>1 / 32$ \\
\hline & 2 meses & $(-)$ & & $-1-$ & $(-)$ & $(-)$ \\
\hline & 5 meses & $(-)$ & & $-/-$ & $(-)$ & $(-)$ \\
\hline & 7 meses & $(-)$ & & $-1-$ & $(-)$ & $(-)$ \\
\hline & 9 meses & $(-)$ & & $-1-$ & $(-)$ & $(-)$ \\
\hline \multirow[t]{4}{*}{$\mathrm{F}}$. & S. de cordón & $(-)$ & & $256 / 256$ & $>1 / 32$ & $>1 / 32$ \\
\hline & 3 meses & $(-)$ & & $256 / 256$ & $>1 / 32$ & $>1 / 32$ \\
\hline & 6 meses & $(-)$ & & $64 / 16$ & $(-)$ & $(-)$ \\
\hline & 1 año $3 \mathrm{~m}$ & $(-)$ & & $64 /-$ & $(-)$ & $(-)$ \\
\hline \multirow[t]{6}{*}{ R. A } & S. de cordón & $(-)$ & & $64 / 32$ & $>1 / 32$ & $>1 / 32$ \\
\hline & $1 \mathrm{mes}$ & $(-)$ & & $64 / 64$ & $>1 / 32$ & $>1 / 32$ \\
\hline & 3 meses & $(-)$ & & $32 /-$ & $>1 / 32$ & $>1 / 32$ \\
\hline & 4 meses & $(-)$ & & $-1-$ & $+1 / 32$ & $+1 / 32$ \\
\hline & 5 meses & $(-)$ & & $-1-$ & $(-)$ & $(-)$ \\
\hline & 9 meses & $(-)$ & & $-1-$ & $(-)$ & $(-)$ \\
\hline
\end{tabular}

$\mathrm{RN}=$ recién nacido $\mathrm{SC}=$ Sangre de cordón $\mathrm{s}=$ semanas

$\mathrm{Xd}=$ xenodiagnóstico $\mathrm{ADs} / \mathrm{cME}=$ aglutinación directa sin y con 2-mercaptoetanol

$\mathrm{HAI}=$ hemoaglutinación indirecta $\mathrm{IFI}=$ inmunofluorescencia indirecta 
No existen diferencias significativas entre la serología en sangre de cordón (Sc) de los RN infectados y los normales. En nuestra experiencia (22) el incremento de IgM específica en los primeros días de vida de los $\mathrm{RN}$ infectados no fue notorio con la reacción de ADs/c2ME (salvo los mellizos, Casos 1 y 2, Tabla 3). Algunos autores tuvieron similares hallazgos y otros no $(17,24,26)$. Depende si la infección intraútero (IU) ocurre en etapa temprana del embarazo o cercana al parto, pero hay que tener en cuenta que se encuentran las IgG maternas enmascarando y también que dependerá de la respuesta y/o madurez inmunológica del feto.

Las aglutininas específicas IgM en $\mathrm{Sc}$ de $\mathrm{RN}$ infectados, en nuestra experiencia, se comportan diferente a lo que observamos en casos de Chagas agudo no congénitos (Tabla 1).

En los RN mellizos, casos 1 y 2, las reacciones serológicas positivas (IFI, AD con 2-ME) al momento del nacimiento, se justificarían por el pasaje transplacentario de Ac maternos, y no permiten diagnosticar un Chagas congénito. Sin embargo la caída de títulos de laADs/c2ME (3 diluciones) demuestra la presencia de IgM específica, que coincide con el Strout positivo, prueba parasitológica que define la infección materno-fetal.

En el RN: Caso 6, si bien la serología fue positiva en Sc, poco aporta al diagnóstico de infección congénita, ya que no se detectó IgM específica, y los Ac anti-IgG pueden ser los maternos. Estos resultados no difieren de los de Sc de RN no infectados hijos de madre chagásica (Tabla 2). La negativización antes de los 6 meses no implica ausencia de infección, pues si ésta se produjo tardíamente en la vida IU, el lactante no alcanzó a elaborar sus Ac, y los de la madre ya han disminuido o desaparecido (vida media de las IgG). En este caso, a los 4 meses en forma incipiente y a los 7 en forma más contundente, detectamos IgM específica. El método parasitológico utilizado fue el Xd, cuya primera lectura es recién a los 30 días. La HAI y la IFI, negativas en el $2^{\circ}$ control a los 4 meses, se positivizaron en el tercer control (7 meses y medio). $\mathrm{Al}$ año y 10 meses todas las técnicas fueron positivas, sin cambio de título en la ADs/c2ME, debido a la presencia de IgG (etapa crónica) (22).

En la Tabla 4 se muestra un caso de Chagas agudo por transplante (tx) renal. Se trata de receptor, varón joven de 28 años, sin antecedentes epidemiológicos para Chagas, con insuficiencia renal terminal. El donante era la madre del receptor, de 54 años, con serologia positiva para Chagas. Parasitemia no determinada. Sin manifestaciones clínicas, ECG y Rx tórax normal. No se administró tratamiento específico. Compartia un haplotipo HLA con el receptor. Por necesidad del caso e imposibilidad de otra solución el órgano fue aceptado. A los 34 días post Tx renal el receptor presentó síntomas. Observamos cómo a los 58 días la ADs/ c2ME permitió detectar la infección en fase aguda con una importante caída en los títulos aglutinantes (7 diluciones de diferencia). Este resultado fue coincidente con la técnica parasitológica de Strout en donde se demostró el parásito. Las otras reacciones serológicas utilizadas fueron la HAI negativa y la IFI positiva en el límite de corte, utilizando anti Ig humana total. 
Tabla 3. CHAGASCONGÉNITO: Clínica, evolución serológica y parasitológica pre y post-tratamiento. Ciudad de Santa Fe, Argentina

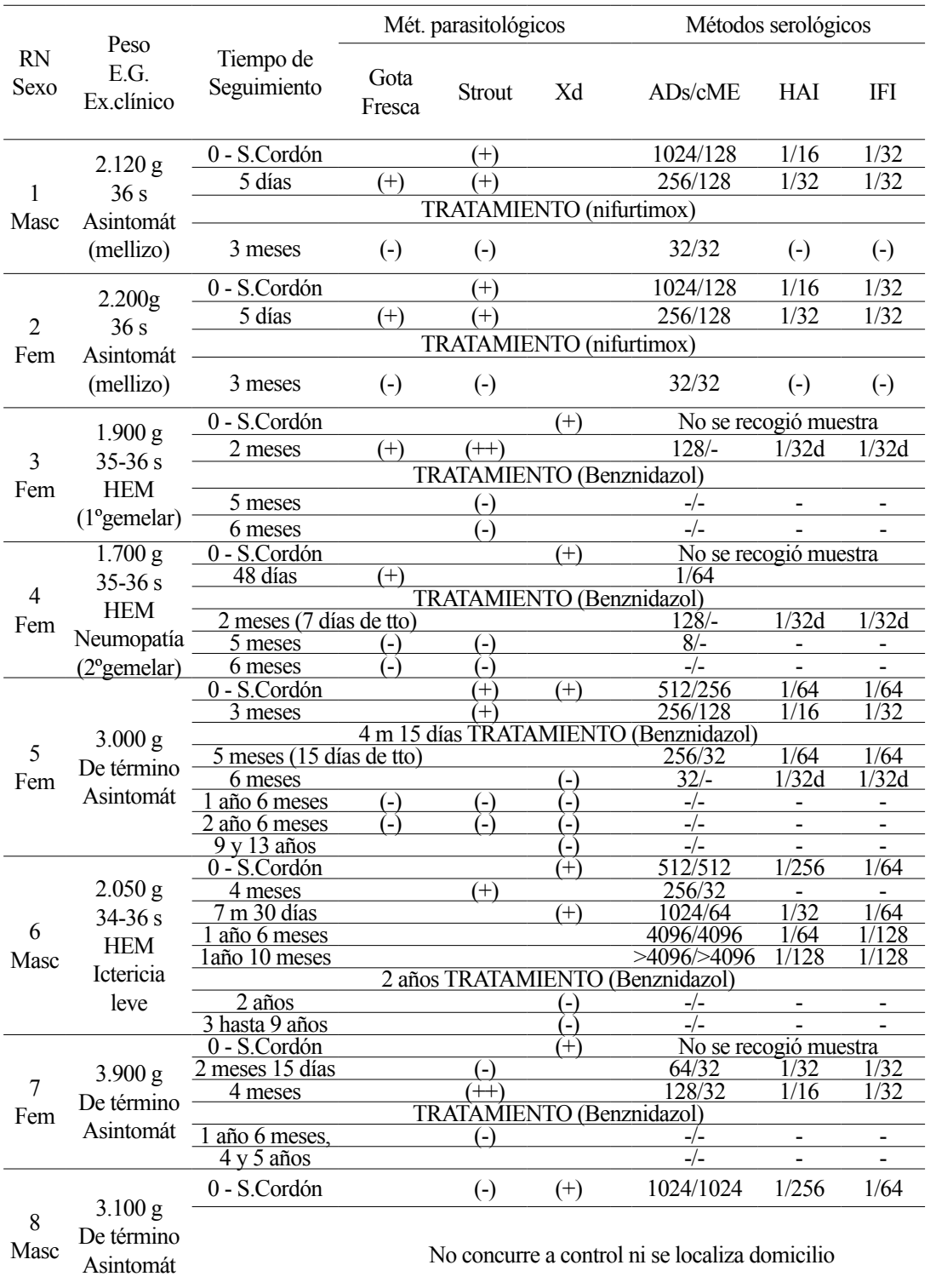

$\mathrm{RN}=$ recién nacido $\mathrm{EG}=$ edad gestacional $\mathrm{SC}=$ Sangre de cordón $\mathrm{s}=$ semanas $\mathrm{HEM}=$ hepatoesplenomegalia $\mathrm{Xd}=\mathrm{xenodiagnóstico} \mathrm{ADs} / \mathrm{cME}=$ aglutinación directa sin $\mathrm{y}$ con 2-mercaptoetanol

$\mathrm{HAI}=$ hemoaglutinación indirecta $\mathrm{IFI}=$ inmunofluorescencia indirecta d=débil 
Tabla 4. Evolución post transplante renal de receptor $\mathrm{S}(-)$ y donante $\mathrm{S}(+)$ para Chagas. Controles serológicos, parasitológicos y clínicos. (S. Fe, Arg)

\begin{tabular}{|c|c|c|c|c|}
\hline \multirow{2}{*}{ Tiempo control } & \multicolumn{3}{|c|}{ Serología } & \multirow{2}{*}{$\begin{array}{c}\text { Parasitemi } \\
\text { Strout }\end{array}$} \\
\hline & $\mathrm{ADs} / \mathrm{cME}$ & HAI & IFI & \\
\hline Pre tx renal & $(-)$ & $(-)$ & $(-)$ & \\
\hline \multicolumn{5}{|l|}{ Post tx renal } \\
\hline 28 días & $(-)$ & $(-)$ & $(-)$ & $(-)$ \\
\hline 34 días & \multicolumn{4}{|c|}{ Síntomas: fiebre, mialgias, artralgias, astenia } \\
\hline 38 días & $(-)$ & $(-)$ & $(-)$ & $(-)$ \\
\hline 48 días & NR & $1 / 8$ & $1 / 32$ & $(-)$ \\
\hline 58 días & $4096 / 32$ & $1 / 8$ & $1 / 32$ & $(+)$ \\
\hline 59 días & \multicolumn{4}{|c|}{ Tto: benznidazol + terapia inmunosupresora } \\
\hline \multicolumn{5}{|c|}{ Post tratamiento antiparasitario específico } \\
\hline 18 días post tto & $1 / 64$ & $1 / 64$ & $1 / 64$ & $\mathrm{NR}$ \\
\hline 29 días & $\mathrm{NR}$ & $1 / 8$ & $1 / 1024$ & $(-)$ \\
\hline 30 días & \multicolumn{4}{|c|}{ interrumpe tto antiparasit-disfunción renal-rechazo tx } \\
\hline 43 días & NR & $1 / 8$ & $1 / 512$ & \\
\hline 60 días & $\mathrm{NR}$ & $1 / 8$ & $1 / 128$ & \\
\hline 81 días & $\mathrm{NR}$ & $1 / 8$ & $1 / 64$ & \\
\hline 109 días & $\mathrm{NR}$ & $1 / 8$ & $1 / 32$ & \\
\hline \multirow{2}{*}{\multicolumn{5}{|c|}{$\downarrow$}} \\
\hline & & & & \\
\hline
\end{tabular}

$\mathrm{S}(-)=$ seronegativo $\mathrm{S}(+)=$ seropositivo

$\mathrm{ADs} / \mathrm{cME}=$ aglutinación directa sin y con 2-mercaptoetanol

$\mathrm{HAI}=$ hemoaglutinación indirecta $\mathrm{IFI}=$ inmunofluorescencia indirecta

$\mathrm{Tx}=$ Transplante $\mathrm{Tto}=$ Tratamiento

En la Tabla 5 vemos tres casos de reactivación de la infección chagásica por tx renal. Observamos receptores de tx renal que previamente tenían Ac anti $T$ cruzi y recibieron riñones de donantes cadavéricos, con serologia negativa para Chagas. $\mathrm{Al}$ estar los receptores inmunosuprimidos, sufrieron una fuerte reactivación de la infección, como se observa en los elevados títulos tanto de la ADs/c2ME como de la HAI y la IFI, todos a expensas de IgG. Aún cuando se observaron tripomastigotes en el líquido ampollar recogido de una paciente trasplantada, el método de Strout no arrojó resultados positivos en ninguno de los casos.

En todos los pacientes que recibieron tratamiento y éste fue efectivo, se observa una paulatina disminución de títulos serológicos hasta su negativización, tanto de la $\mathrm{ADs} / \mathrm{c} 2 \mathrm{ME}$ como de las otras reacciones serológicas.

Además, en un estudio previo sobre 2.456 sueros (6), comparando los resultados de AD, HAI e IFI, hallamos asociación entre ellas $\left(\chi^{2}, \mathrm{p}<0,05\right)$, y aplicando el test de McNemar entre IFI y AD-2ME se acepta la hipótesis de igualdad $(\mathrm{p} \leq 0,05)$ (no hubo casos de infección aguda en la muestra). Por lo tanto, se encontró una estrecha asociación entre las tres reacciones serológicas utilizadas $(\mathrm{p}<0,05)$. Además se halló identidad entre las reacciones de IFI y de $\mathrm{AD}$, pero no se encontró lo mismo con la reacción de HAI (rápida), por lo que consideramos tiene vigencia la recomendación de la Organización Panamericana de la Salud sobre la 
necesidad de concordancia de, por lo menos, dos métodos serológicos de certeza de la infección chagásica.

Tabla 5. Reactivación de Chagas crónico por transplante renal. Tres casos (S. Fe, Arg)

Caso 1

Receptor: Mujer de 33 años, de Z.E. (Formosa, lím con Chaco) $\mathbf{S ( + )}$ p/Chagas Donante: Cadavérico. S(-) para Chagas.

\begin{tabular}{|c|c|c|c|c|}
\hline \multirow{2}{*}{ Tiempo control } & \multicolumn{3}{|c|}{ Serología } & \multirow{2}{*}{$\begin{array}{c}\text { Parasitemia } \\
\text { Strout }\end{array}$} \\
\hline & ADs/cME & HAI & IFI & \\
\hline Pre tx & $512 / 512$ & $1 / 64$ & $1 / 128$ & \\
\hline \multicolumn{5}{|l|}{ Post tx renal } \\
\hline 30 días & $256 / 128$ & $1 / 256$ & $1 / 64$ & \\
\hline 56 días & $\begin{array}{l}\text { Sintomatología: } \\
\text { Biopsia de piel: }\end{array}$ & $\begin{array}{l}\text { ma nud } \\
\text { histiocit }\end{array}$ & $\begin{array}{l}\text { os inf), } \\
\text { igotes }\end{array}$ & \\
\hline 60días & $1024 / 1024$ & $1 / 128$ & $1 / 64$ & $(-)$ \\
\hline 75 días & $8192 / 8192$ & $1 / 256$ & $1 / 256$ & \\
\hline 90 días & $8192 / 8192$ & $1 / 128$ & $1 / 256$ & \\
\hline
\end{tabular}

Caso 2

Receptor: Mujer de 43 años, de Z.E. (Dpto Vera, Pcia Sta Fe) S(+) p/Chagas Donante: Cadavérico. S(-) para Chagas.

\begin{tabular}{|c|c|c|c|c|}
\hline \multirow{2}{*}{ Tiempo control } & \multicolumn{3}{|c|}{ Serología } & \multirow{2}{*}{$\begin{array}{c}\text { Parasitemia } \\
\text { Strout }\end{array}$} \\
\hline & $\mathrm{ADs} / \mathrm{cME}$ & HAI & IFI & \\
\hline Pre tx & $(+)$ & $(+)$ & $(+)$ & \\
\hline \multicolumn{5}{|l|}{ Post tx renal } \\
\hline 30 días & $256 / 128$ & $1 / 128$ & $1 / 256$ & \\
\hline 58 días & $\begin{array}{l}\text { Sintomatología: } \\
\text { Examen en fresc } \\
\text { Biopsia de piel: }\end{array}$ & $\begin{array}{l}\text { ema nud } \\
\text { lo ampol } \\
\text { histiocit }\end{array}$ & $\begin{array}{l}\text { muslo } \\
\text { tigotes } \\
\text { gotes }\end{array}$ & \\
\hline 60 días & $4096 / 4096$ & $1 / 128$ & $1 / 256$ & $(-)$ \\
\hline \multicolumn{5}{|c|}{ Tto: benznidazol (5mg/kg/día) durante 30 días } \\
\hline 75 días & $4096 / 4096$ & $>1 / 256$ & $1 / 256$ & \\
\hline 90 días & $4096 / 4096$ & $>1 / 512$ & $1 / 512$ & \\
\hline Caso 3 & $\begin{array}{l}\text { Receptor: Mujer } \\
\text { Donante: Cadav }\end{array}$ & $\begin{array}{l}\text {, proced } \\
\text { para Cha }\end{array}$ & yá (E. & Chagas \\
\hline \multirow{2}{*}{ Tiempo control } & & Serologí & & Parasitemia \\
\hline & ADs/cME & HAI & IFI & Strout \\
\hline Pre tx & $4096 / 2048$ & $1 / 256$ & $1 / 256$ & \\
\hline \multicolumn{5}{|l|}{ Post tx renal } \\
\hline 68 días & Sintomas: fiebre, & ucosa or & temat & \\
\hline 68 días & $8192 / 8192$ & $1 / 256$ & $1 / 128$ & \\
\hline
\end{tabular}

Z.E. = zona endémica $\mathrm{S}(-)=$ seronegativo $\mathrm{S}(+)=$ seropositivo

$\mathrm{ADs} / \mathrm{cME}=$ aglutinación directa sin y con 2-mercaptoetanol $\mathrm{HAI}=$ hemoaglutinación indirecta $\mathrm{IFI}=$ inmunofluorescencia indirecta $\mathrm{t} x=$ Transplante $\mathrm{Tto}=$ Tratamiento

Es de advertir que un resultado de "ADs/c2ME=128-" debe tenerse en consideración, ya que si bien puede deberse a Ac inespecíficos, también se puede presentar al inicio de una infección o en la evolución post tratamiento tripanocida (Tabla 1: casos 1 y 5 post-tratamiento, caso 6 pre-tratamiento. Tabla 3: casos 3 pre-tratamiento y 4 post-tratamiento). 


\section{CONCLUSIONES}

Los casos presentados muestran la utilidad de la técnica de Aglutinación Directa con y sin 2-ME para detectar infección chagásica.

Por la precocidad en su positivización y por las posibilidades que brinda de diferenciar una infección aguda de una crónica, o la presencia de Ac maternos transferidos pasivamente de aquellos elaborados por el sistema inmune del recién nacido $(8,9,10,16,17,18,21,24,26)$ es una técnica altamente recomendable, siempre en simultáneo con otros test serológicos y parasitológicos según corresponda $(6,15)$. Además la reacción de $\mathrm{AD}$ es de sencilla realización, relativamente económica y no requiere instrumental costoso ni sofisticado, por lo que puede realizarse aún en centros de salud de baja complejidad. Es una alternativa que aún debe tenerse en cuenta para el diagnóstico de tripanosomiasis americana.

\section{ABSTRACT}

Usefulness of the direct agglutination test for the diagnosis of chagasic infection

The direct agglutination technique for chagasic infection diagnosis is easy to perform and inexpensive. It has good sensitivity and specificity when used in conjunction with other serological and/or parasitological techniques. It has been replaced with other reactions with faster results and easiness to read (i.e. immunoenzymatic assay (ELISA) and indirect hemagglutination). Currently it is difficult to obtain commercial kits. In the present paper we present a series of cases that show the usefulness of the direct agglutination test to early determine acute and/or congenital infection and to differentiate acute from chronic infections.

KEY WORDS: Chagas. Diagnosis. Direct agglutination.

\section{BIBLIOGRAFÍA}

1. Alvarez M, Cerisola JA, Rohwedder RW. Test de inmunofluorescencia para diagnóstico de la enfermedad de Chagas. Bol Chil Parasitol XXIII: 4-9, 1968.

2. Averbach S, Averbach B, Yanovsky JF, Schmuñis GA. Specific agglutinins as simple methods for detections of acute or cronic Toxoplasma infection. Medicina (B Aires) 35: 469, 1975.

3. Boyden SV. The adsorption of proteins on erythrocytes treated with tannic acid and subsequent hemagglutination by antiprotein sera. J Exp Med 93: 107-120, 1951.

4. Cerisola JA, Rohweder R, Segura EL, Del Prado CE, Alvarez M, Martini GJW. El xenodiagnóstico. Normatización. Instituto Nacional para Diagnostico e Investigación de la enferemedad de Chagas, Dr Mario Fatala Chaben (INDIECH), Buenos Aires, Argentina, 1974.

5. Cerisola JA. Diagnóstico de Laboratorio de la enfermedad de Chagas. Anales F.L.I.P.: 42-43, 1974.

6. Dávila E, Streiger M, Bovero N, Fabbro D. Comparación de 3 reacciones serológicas para infección chagásica. Acta Bioquim Clin Latinoam 16: 99-102, 1982. 
7. Fabbro D, Velazquez E, Mendoza N, Streiger M, Arias E, Denner S, del Barco M, Amicone N, Pravia C, Malagrino N, Ruiz A. Evaluación de ELISA F29 como marcador de eficacia del tratamiento etiológico en la enfermedad de Chagas. Parasitol latinoam 62: 103-111, 2007.

8. Freilij H, Altcheh J. Chagas congénito. En: Storino R, Milei J (eds). Enfermedad de Chagas. Ed. Buenos Aires: Mosby Doyma. 267-278, 1994.

9. Freilij H, Altcheh J. Congenital Chagas' disease: Diagnostic and clinical aspects. Clin Infect Dis 21: 551-555, 1995.

10. Gonzalez Cappa S, Menes S, Schmuñis GA, Szarfman A, Vattuone NH, Yanovsky JF. La detección de aglutininas específicas en el diagnóstico de la enfermedad de Chagas (Tripanosomiasis Americana). Medicina (B Aires) 36: 364-375, 1976.

11. Harith AE, Kolk AH, Kager PA, Leeuwenburg J, Muigai R, Kiugu S, Kiugu S, Laarman JJ. A simple and economical direct agglutination test for serodiagnosis and sero-epidemiological studies of visceral leishmaniasis. Trans R Soc Trop Med Hyg 80: 583-586, 1986.

12. Hoshino Shimizu S, Camargo M \& Nagasse TK. A stable polisaccharide-hemagglutination reagent for the diagnosis of acute or recent trypanosoma cruzi infections. Rev Inst Med Trop Sao Paulo 20: 208-212, 1978.

13. Illia C, D'Agostino L, Willie J, Mazziotta D. Evaluación externa de calidad para el diagnóstico serológico de la Enfermedad de Chagas- 3 años de evolución. Acta Bioquim Clin Latinoam 39: 355-357, 2005.

14. Lorca M, Contreras MC, Salinas P, Guerra A, Raychaudhuri S. Evaluación de una prueba rápida para el diagnóstico de la infección por Trypanosoma cruzi en suero. Parasitol. Latinoam 63: 29-33. 2008.

15. Luquetti AO. Use of Trypanosoma cruzi defined proteins for diagnosis-multicentre trial: serological and technical aspects. Mem Inst Oswaldo Cruz 85: 497-505, 1990.

16. Schmuñis GA, Szarfman A. La enfermedad de Chagas congénita. Medicina (B Aires) 37: 47-53, 1977.

17. Schmuñis GA, Szarfman A, Coarasa L, Guilleron C, Peralta JM. Anti-Trypanosoma cruzi Agglutinins in Acute Human Chagas' Disease. Am. J Trop Med Hyg 29: 170-178, 1980.

18. Schmuñis GA. A resposta immune-humoral na infecção humana recente pelo Trypanosoma cruzi. [Tesis para obtener grado de Doctor-Instituto de Microbiología, Univ Federal Río de Janeiro, 1978] Rev Patol Trop 20: 51-146, 1991.

19. Storni P. Sensibilidad de la técnica de "aglutinación directa" para el diagnostic de la enfermedad de Chagas. Medicina (B Aires) 36: 159-160, 1976.

20. Streiger ML, Bovero NM, Dávila EV. Reacción de inmunofluorescencia indirecta para el diagnóstico de la infección chagásica. Conservación de improntas. Medicina (B Aires) 40: 250-251, 1980.

21. Streiger M, Fabbro D, del Barco M, Beltramino R, Bovero N. Chagas congénito en la ciudad de Santa Fe. Diagnóstico y tratamiento. Medicina (B Aires) 55: 125-133, 1995.

22. Streiger ML, Bovero NM, Beltramino R, Arias ED, del Barco ML, Fabbro DL. Chagas congénito. Un caso que deja muchas enseñanzas. Revista FABICIB 3: 137-142, 1999.

23. Strout RG. A method for concentrating hemoflagellates. J Parasitol 48: 100, 1962.

24. Szarfman A, Urman J, Otalora A, Larguía A, Yanovsky JF. Specific agglutinins and immunoglobulin levels in congenital Chagas infection. Medicina (B Aires) XXXV: 245-250, 1975.

25. Vattuone N, Yanovsky J. Trypanosoma cruzi: Agglutination activity of enzyme treated epimastigotes. Experimental Parasitology 30: 349-355, 1971.

26. Votta RA, Marchese CA, Sousa Martínez F, Lautrec L, Gonzalez CA, Arendt FF, Toranzos A, Fernández Díaz HG. La enfermedad de Chagas en la embarazada y en el recién nacido. $3^{\text {a }}$ Sesión Científica Soc Obst y Ginec Bs As:56-68, 1974.

27. Yanovsky JF. La Reacción de aglutinación directa para Chagas. Bioq Clin 8: 47-54, 1974. 